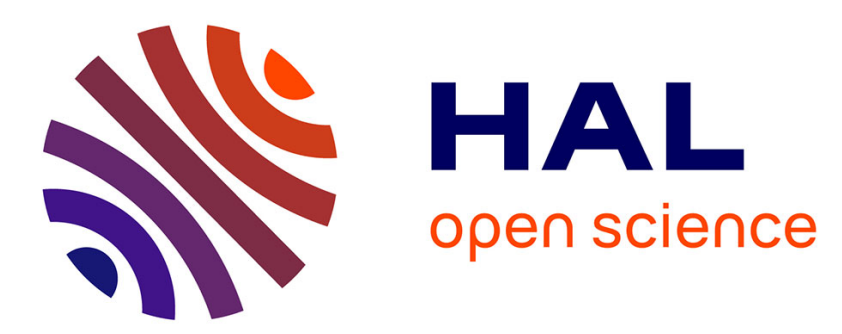

\title{
Physiological markers of challenge and threat mediate the effects of performance-based goals on performance
} Aïna Chalabaev, Brenda Major, François Cury, Philippe Sarrazin

\section{To cite this version:}

Aïna Chalabaev, Brenda Major, François Cury, Philippe Sarrazin. Physiological markers of challenge and threat mediate the effects of performance-based goals on performance. Journal of Experimental Social Psychology, 2009, 45 (4), pp.991. 10.1016/j.jesp.2009.04.009 . hal-00687726

\section{HAL Id: hal-00687726 https://hal.science/hal-00687726}

Submitted on 14 Apr 2012

HAL is a multi-disciplinary open access archive for the deposit and dissemination of scientific research documents, whether they are published or not. The documents may come from teaching and research institutions in France or abroad, or from public or private research centers.
L'archive ouverte pluridisciplinaire HAL, est destinée au dépôt et à la diffusion de documents scientifiques de niveau recherche, publiés ou non, émanant des établissements d'enseignement et de recherche français ou étrangers, des laboratoires publics ou privés. 


\section{Accepted Manuscript}

Physiological markers of challenge and threat mediate the effects of performance-based goals on performance

Aïna Chalabaev, Brenda Major, François Cury, Philippe Sarrazin, François Cury

PII:

S0022-1031(09)00090-0

DOI:

10.1016/j.jesp.2009.04.009

Reference:

YJESP 2247

To appear in:

Journal of Experimental Social Psychology

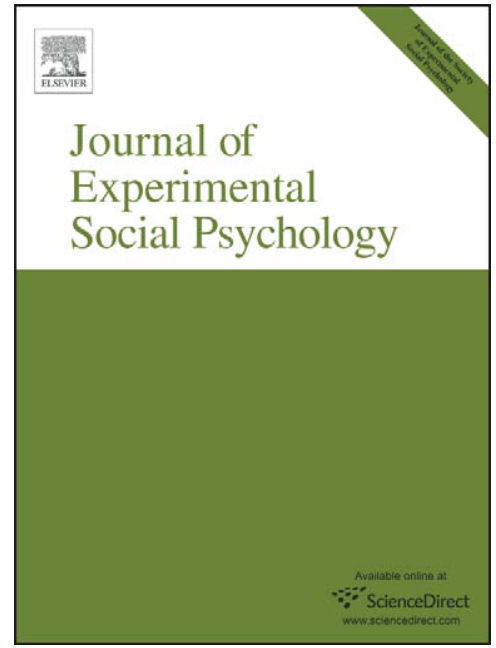

Received Date: $\quad 23$ October 2008

Revised Date: $\quad 4$ March 2009

Please cite this article as: Chalabaev, A., Major, B., Cury, F., Sarrazin, P., Cury, F., Physiological markers of challenge and threat mediate the effects of performance-based goals on performance, Journal of Experimental Social Psychology (2009), doi: 10.1016/j.jesp.2009.04.009

This is a PDF file of an unedited manuscript that has been accepted for publication. As a service to our customers we are providing this early version of the manuscript. The manuscript will undergo copyediting, typesetting, and review of the resulting proof before it is published in its final form. Please note that during the production process errors may be discovered which could affect the content, and all legal disclaimers that apply to the journal pertain. 
Achievement goals and psychophysiology 1

\section{Running head: CHALLENGE AND THREAT IN ACHIEVEMENT GOALS}

Physiological markers of challenge and threat mediate the effects of performance-based goals on performance

Aïna Chalabaev

University of Grenoble, France and University of California, Santa Barbara

$$
\text { Brenda Major }
$$

University of California, Santa Barbara

François Cury

CNRS Provence University and Toulon Var South University, France

Philippe Sarrazin

University of Grenoble, France

Author's Note: Aina Chalabaev is now at the University of Nice Sophia-Antipolis, Nice,

France. This research was supported by a Marie Curie Outgoing International Fellowship from the European Commission. We wish to express our gratitude to Heidi Nyberg, Kathryn Chaimov, and Stacy Springmeyer for their help in collecting data.

Correspondence concerning this article should be addressed to Aïna Chalabaev, UFR

STAPS, Université de Nice Sophia-Antipolis, 261 route de Grenoble, 06205 Nice cedex

3, France. e-mail: aina.chalabaev@ unice.fr; phone: +33 (0)4 922965 24; fax: +33 (0)4

92296549. 
Achievement goals and psychophysiology 2

\begin{abstract}
We predicted that adopting a performance-approach vs. performance-avoidance goal would lead to physiological responses characteristic of psychological states of challenge vs. threat appraisals, respectively. Furthermore, we predicted that these states would mediate the effects of goals on performance. Twenty-seven undergraduate females performed a task described as identifying either exceptionally strong performers (performance-approach goal) or exceptionally weak performers (performance-avoidance goal). Participants' cardiovascular reactivity (CVR) was recorded while they performed the task. As predicted, participants in the performance-approach goal condition performed better on the task than did those in the performance-avoidance goal condition. Also as predicted, those in the former condition exhibited a challenge pattern of CVR whereas those in the latter condition exhibited a threat pattern of CVR. Furthermore, physiological responses mediated the effects of performance-based goals on performance.
\end{abstract}

Keywords: achievement goals, avoidance, approach, challenge, threat, cardiovascular responses, performance. 
Physiological markers of challenge and threat mediate the effects of performance-based goals on performance

Why do some students strive for success whereas others give up from even the smallest difficulty? Over the past decades, the achievement goal perspective (Elliot, 2005) has attempted to answer this question. According to this theory, the goals that people adopt within achievement situations create a framework for how they interpret, evaluate, and act on achievement-relevant information. For example, some people adopt a performance-approach goal, trying to perform well compared to others, whereas others adopt a performance-avoidance goal, trying to avoid performing poorly relative to others (Elliot \& Church, 1997). Adopting a performance-approach goal is associated with more adaptive achievement outcomes than adopting a performance-avoidance goal, including lower anxiety, higher task absorption, more intrinsic motivation and better performance (e.g., Cury, Elliot, Sarrazin, Da Fonseca, \& Rufo, 2002; Elliot \& Harackiewicz, 1996; for a review see Elliot, 2005).

Why do these goals have such different implications for achievement? One possibility is that type of goal influences the ways in which people appraise achievement tasks, i.e., assess the demands of the task and their resources for meeting those demands (Lazarus \& Folkman, 1984). According to Elliot and Harackiewicz (1996), in a performance-approach goal orientation, individuals perceive the achievement setting as a challenge, i.e. they appraise their resources as exceeding task demands. In contrast, in a performance-avoidance goal orientation, individuals construe the achievement setting as a threat, because they perceive the demands of the task as outweighing their resources (Blascovich \& Tomaka, 1996; Lazarus \& Folkman, 1984). Indeed, focusing on avoiding 
demonstrating one's incompetence may pose a threat to self-esteem, thus increasing the psychological danger (demands) associated with a task compared to focusing on demonstrating one's competence.

Challenge and threat appraisals are key constructs because they are supposed to explain why performance-approach and avoidance goals have different consequences on achievement. However, to date, no research has tested whether these appraisals mediate the differential effects of performance-based goals on performance. This was the aim of the current research.

Using self-report measures, Elliot and Harackiewicz (1996) found that participants who endorsed a performance-approach goal (relative to a performanceavoidance goal) appraised an achievement task as a more of a challenge, although performance-based goals were unrelated to threat appraisals. Nevertheless, these appraisals were not tested as mediators. One reason that may explain these results is that challenge and threat may be difficult to assess via self-reports. Thus, the current research used physiological markers of challenge and threat states identified and validated in prior research (see Blascovich, 2008 for a review) in addition to self-reports. Physiological measures have several methodological advantages over self-reports; most notably, as they can be continuously and covertly recorded on line, they are less susceptible to effects of reappraisal and discounting and to self-presentational biases that can occur when one's abilities are in question. Elliot, Maier, Moller, Friedman, and Meinhardt (2007) demonstrated the utility of using physiological measures to study achievement motivation processes. They showed that activating avoidance motivation using a nonconscious prime 
(the color red) affected both performance and a physiological measure of avoidance motivation (cortical activation).

According to the biopsychosocial model (BPSM) of challenge and threat (e.g., Blascovich \& Tomaka, 1996; Blascovich \& Mendes, 2000), within motivated performance situations, four measures of cardiovascular reactivity (CVR) can be used to differentiate challenge and threat states: heart rate (HR), ventricular contractility (VC; an index of the left ventricle's contractile force), cardiac output (CO; the amount of blood in liters pumped by the heart per minute), and total peripheral resistance (TPR; an index of net constriction vs. dilation in the arterial system). Challenge is indexed by an increase in $\mathrm{CO}$ and a decrease in TPR, indicating increased cardiac efficiency and vasodilation in the arterioles, which provides greater blood flow to the periphery. In contrast, threat is indexed by little or no change in $\mathrm{CO}$ and no change or an increase in TPR, indicating less efficient cardiac output and vasoconstriction. Task engagement is common to both challenge and threat states and is indexed by an increase in HR and VC from baseline. A number of studies have provided correlational, experimental, and predictive support for these differential patterns of CVR as measures of challenge and threat appraisals (see Blascovich, 2008). For example, Blascovich, Seery, Mugridge, Weisbugh and Norris (2004) showed that baseball players who exhibited a challenge pattern of CVR while giving a baseball-related speech performed significantly better on the field in the six months following the experiment compared to those who exhibited a threat pattern of CVR during the speech.

Integrating the BPSM with achievement goal theory provides a novel way of examining the role of appraisals in performance-based goals processes. Based on the 
above literature, we generated the following predictions. First, we hypothesized that individuals induced to adopt a performance-approach goal would perform better on a problem-solving task than would individuals induced to adopt a performance-avoidance goal. Second, we predicted that the former would display a pattern of CVR indicative of challenge whereas the latter would display a pattern of CVR indicative of threat. We also predicted that the former would report feeling more challenged and less threatened than the latter. Third, we predicted that the effect of performance goal induction on task performance would be mediated by challenge and threat states as indexed by patterns of CVR and self-reports.

Method

\section{Participants}

Twenty-seven female undergraduates at the University of California took part in this study for course credit or $\$ 10$.

Procedure and Measures

During a prescreening survey participants reported their score on the quantitative section of the Scholastic Aptitude Test (SAT). Upon arriving individually at the laboratory, a female experimenter blind to hypotheses and condition applied CV sensors to participants, who sat in an upright chair facing a computer monitor at eye level. Participants were asked to sit quietly for five minutes, during which baseline CV data were recorded.

$\mathrm{CV}$ measures were recorded noninvasively and continuously via impedance cardiography (Minnesota Impedance Cardiograph, Model 304B), electrocardiography (Coulbourn ECG amplifier/coupler, Model S75-11), and continuous blood pressure 
(Cortronics, Model 7000) recording equipment (for more details see Blascovich et al., 2004). Following the rest period, tape-recorded instructions informed participants that the research sought to understand psychophysiological processes underlying differences in problem-solving ability between individuals and reminded them that problem-solving skills are crucial to performance in many important subjects in college. Participants were then randomly assigned to one of two performance-based goal conditions, using an instructional manipulation based on Brown and Josephs (1999). Instructions for the performance-avoidance condition follow, with performance-approach goal instructions shown in parentheses.

"The particular test you will be taking today is designed to help us identify people who are exceptionally weak (strong) in their problem-solving reasoning abilities. Your performance on this test will not be scored like most normal tests, but rather will be classified as either above or below a predetermined cutoff score. If you score below (above) the cutoff score, this suggests that you are exceptionally weak (strong)—in other words, well below (above) average in your problem-solving reasoning abilities. However, scoring above (below) the cutoff score tells us little or nothing about your problem-solving abilities and potential. You may be below average, average, or even above average. Thus, this test and the scoring method used with it are designed only to separate those who are especially weak (strong) from everyone else."

Because normative comparison is an important component of performance-based goals (e.g., Elliot \& Thrash, 2001), participants were also told that at the end of the 
experiment, they would be provided with information regarding how they did on the problem-solving test compared to other university students.

Participants next completed a manipulation check (indicating whether the purpose of the task was to select students who were exceptionally strong or weak) and indicated on a 1 to 7 scale the extent to which they felt "challenged" and "worried" as they anticipated doing the task (e.g., Elliot \& Harackiewicz, 1996).

They then performed the problem-solving task. This was composed of 10 multiple-choice word problems with 5 answer choices, taken from a Graduate Record Examination practice book. Problems were presented on the computer monitor in front of the participants. In order to prevent movement artefacts caused by writing during the test that could interfere with measuring equipment participants had to solve the problems mentally and verbalize their responses. The computer screen automatically advanced to the next problem after one minute had passed. Performance was scored using the standard formula for scoring GRE: correct items received one point and incorrect items received a deduction of one point divided by the number of response options for that item (i.e., 5) the correction factor for guessing. Following task completion, participants were thanked and fully debriefed.

\section{Results}

\section{Preliminary analyses}

We first analyzed the manipulation checks to establish that the manipulation was perceived as intended. It was. Following standard practices, we then computed reactivity values for $\mathrm{CV}$ responses by subtracting the average value of the last baseline minute from the mean of the first three minutes of the task. Only the first task minutes were analyzed 
because $\mathrm{CV}$ responses have been shown to peak in the first minutes of the task (Blascovich \& Tomaka, 1996). We first checked that participants were engaged in the task by testing HR and VC reactivity against zero. Two-tailed $t$ tests showed significant differences from zero in HR reactivity, $t(25)=4.70, p<.001$, and $\mathrm{VC}$ reactivity, $t(25)=$ $3.99, p<.001$, confirming that participants were engaged during the first minutes of the task.

Primary analyses

Effects of goal on task performance. To test our first prediction, we conducted a multiple regression analysis predicting task performance from goal type (we dummycoded performance-approach goal as 1 and performance-avoidance goal as 0 ). This analysis controlled for SAT scores in order to test the impact of performance-based goals independently of objective ability constructs (e.g., Elliot \& McGregor, 1999). As predicted, performance-approach goal participants $(M=5.87)$ performed significantly better than performance-avoidance goal participants $(M=4.19), \beta=.37, p=.02$.

Effects of goal on physiological responses. To test our second prediction, we performed multiple regression analyses predicting CO and TPR reactivity from goal type, controlling for SAT and baseline measures of CO or TPR. As predicted, performanceapproach goal participants showed significantly higher levels of CO reactivity, $\beta=.53, p$ $=.01$, and significantly lower levels of TPR reactivity, $\beta=-.56, p=.005$, than performance-avoidance goal participants. As shown in Figure 1, performance-approach goal participants exhibited a CVR pattern consistent with a psychological state of challenge, whereas performance-avoidance goal participants exhibited a CVR pattern consistent with a psychological state of threat. 
Effects of goal on self-reports. We performed similar regression analyses examining the effects of goal type on self-reported feelings of challenge and threat, controlling for SAT scores. Performance-approach goal participants reported feeling significantly more challenged prior to the task than did performance-avoidance goal participants, $\beta=.56, p<.01$. Analysis of the threat item "I feel worried" revealed no effect of goal type.

Mediational analyses. To test our third prediction, we conducted meditational analyses following procedures recommended by Baron and Kenny (1986). First, we regressed task performance on Goal Type, SAT, CO reactivity and baseline CO. Consistent with predictions, $\mathrm{CO}$ reactivity was positively related to performance, $\beta=.53$, $p<.001$. In addition, inclusion of CO reduced the beta for Goal Type to nonsignificance ( $\beta=.12$ ); a Sobel test showed that this reduction in magnitude of effect was significant $(Z$ $=2.34, p=.02)($ see Figure 2). Next, we regressed task performance on Goal Type, SAT, TPR reactivity and baseline TPR. TPR reactivity was negatively related to performance, $\beta=-.36, p=.04$. Furthermore, inclusion of TPR reactivity in the model reduced the beta for Goal Type to nonsignificance $(\beta=.21)$; the Sobel test was marginally significant, $Z=$ $1.74, p=.08$

Finally, we regressed task performance on Goal Type, SAT, and self-reported feelings of challenge. Self-reported challenge was unrelated to performance, $\beta=-.12$ and did not qualify as a mediator of the effects of goal on task performance.

\section{Discussion}

Researchers have speculated that performance-approach goals may lead people to experience achievement situations as a challenge whereas performance-avoidance goals 
Achievement goals and psychophysiology 11

may lead people to experience achievement situations as a threat (Elliot \& Harackiewicz, 1996). Further, these differential states are thought to potentially mediate effects of goals on performance. The current study was the first to directly test this hypothesis by articulating the achievement goal theory with the BPSM of challenge and threat. Collectively, results indicated that threat and challenge states, as measured by patterns of CVR but not by self-report, mediated the effect of induced goal type on performance.

Consistent with prior research (see Elliot, 2005), participants induced to adopt a performance-approach goal performed better on a problem-solving task than those induced to adopt a performance-avoidance goal. Inducing these different performancebased goals also led to different patterns of CVR. Specifically, participants pursuing a performance-approach goal exhibited a physiological pattern characteristic of challenge during the task whereas participants pursuing a performance-avoidance goal exhibited a physiological pattern characteristic of threat. Most importantly, we found that these psychological states, as indexed by physiology, mediated the effect of achievement goals on task performance. These results are, to our knowledge, the first empirical evidence do demonstrate this.

Similar to Elliot and Harackiewicz (1996), we also found that inducing a performance-approach goal led to greater self-reported feelings of challenge, whereas inducing a performance-avoidance goal did not lead to greater self-reported feelings of threat. Self-reported challenge, however, did not mediate the effects of goal type on performance. Challenge and threat states may be difficult to assess via self-reports, however, either because participants are unable or unwilling to report on these 
experiences. This study confirms that indirect measures may be more effective ways of assessing these states (Blascovich et al., 2004).

One limitation of this study is the lack of a control group in which no achievement goal was induced. Consequently, we do not know if the approach goal induction had facilitative effects or if the avoidance goal induction had debilitating effects. Although characteristic of many studies in this area (e.g., Cury et al., 2002; Elliot et al., 2006; Elliot \& Harackiewicz, 1996; Senko \& Harackiewicz, 2005), this should be addressed in future research.

In conclusion, this study is the first to demonstrate that challenge and threat psychological states, indexed by physiological patterns of CVR, are not only differentially induced by performance-approach vs. performance-avoidance goals, respectively, but also mediate the effects of performance-based goal on performance. 
Achievement goals and psychophysiology 13

\section{References}

Baron, R. M., \& Kenny, D. A. (1986). The moderator-mediator variable distinction in social psychological research: Conceptual, strategic, and statistical considerations. Journal of Personality and Social Psychology, 51, 1173-1182.

Blascovich, J. (2008). Challenge and threat. In A. J. Elliot (Ed.), Handbook of approach and avoidance motivation. Mahwah, NJ: Lawrence Erlbaum Associates.

Blascovich, J., \& Mendes, W. B. (2000). Challenge and threat appraisals: The role of affective cues. In J. P. Forgas (Ed.), Feeling and thinking: The role of affect in social cognition (pp. 59-82). Paris: Cambridge University Press.

Blascovich, J., Seery, M. D., Mugridge, C. A., Norris, R. K., \& Weisbuch, M. (2004). Predicting athletic performance from cardiovascular indexes of challenge and threat. Journal of Experimental Social Psychology, 40, 683-688.

Blascovich, J., \& Tomaka, J. (1996). The biopsychosocial model of arousal regulation. In M. P. Zanna (Ed.), Advances in experimental social psychology (Vol. 28, pp. 151). San Diego, US: Academic Press.

Brown, R. P., \& Josephs, R. A. (1999). A burden of proof: Stereotype relevance and gender differences in math performance. Journal of Personality and Social Psychology, 76, 246-257.

Cury, F., Elliot, A., Sarrazin, P., Da Fonseca, D., \& Rufo, M. (2002). The trichotomous achievement goal model and intrinsic motivation: A sequential mediational analysis. Journal of Experimental Social Psychology, 38, 473-481. 
Achievement goals and psychophysiology 14

Elliot, A. J. (2005). A conceptual history of the achievement goal construct. In A. Elliot \& C. Dweck (Eds.), Handbook of competence and motivation (pp. 52-72). New York: Guilford Press.

Elliot, A. J., \& Church, M. A. (1997). A hierarchical model of approach and avoidance achievement motivation. Journal of Personality and Social Psychology, 72, 218232.

Elliot, A. J., Cury, F., Fryer, J. W., \& Huguet, P. (2006). Achievement goals, selfhandicapping, and performance attainment: A mediational analysis. Journal of Sport \& Exercise Psychology, 28, 344-361.

Elliot, A. J., \& Harackiewicz, J. M. (1996). Approach and avoidance achievement goals and intrinsic motivation: A mediational analysis. Journal of Personality and Social Psychology, 70, 461-475.

Elliot, A. J., Maier, M. A., Moller, A. C., Friedman, R., \& Meinhardt, J. (2007). Color and psychological functioning: The effect of red on performance attainment. Journal of Experimental Psychology: General, 136, 154-168.

Elliot, A. J., \& McGregor, H. A. (1999). Test anxiety and the hierarchical model of approach and avoidance achievement motivation. Journal of Personality and Social Psychology, 76, 628-644.

Elliot, A. J., \& Thrash, T. M. (2001). Achievement goals and the hierarchicalmodel of achievement motivation. Educational Psychology Review, 13, 139-156.

Senko, C. M., \& Harackiewicz, J. M. (2005). Achievement goals, performance and task interest: Why perceived difficulty matters. Personality and Social Psychology Bulletin, 31, 1739-1753. 
Sherwood, A., Allen, M. T., Fahrenberg, J., Kelsey, R. M., Lovallo, W. R., \& Van Dooren, L. J. P. (1990). Methodological guidelines for impedance cardiography. Psychophysiology, 27, 1-23.

Vick, S. B., Seery, M. D., Blascovich, J., \& Weisbuch, M. (2008). The effect of gender stereotype activation on challenge and threat motivational states. Journal of Experimental Social Psychology, 44, 624-630. 
Achievement goals and psychophysiology 16

\section{Figure Captions}

Figure 1. Adjusted CO and TPR reactivity means by goal type during task performance.

Figure 2. Mediation of goal type effect on performance by cardiovascular responses. 
Figure 1.
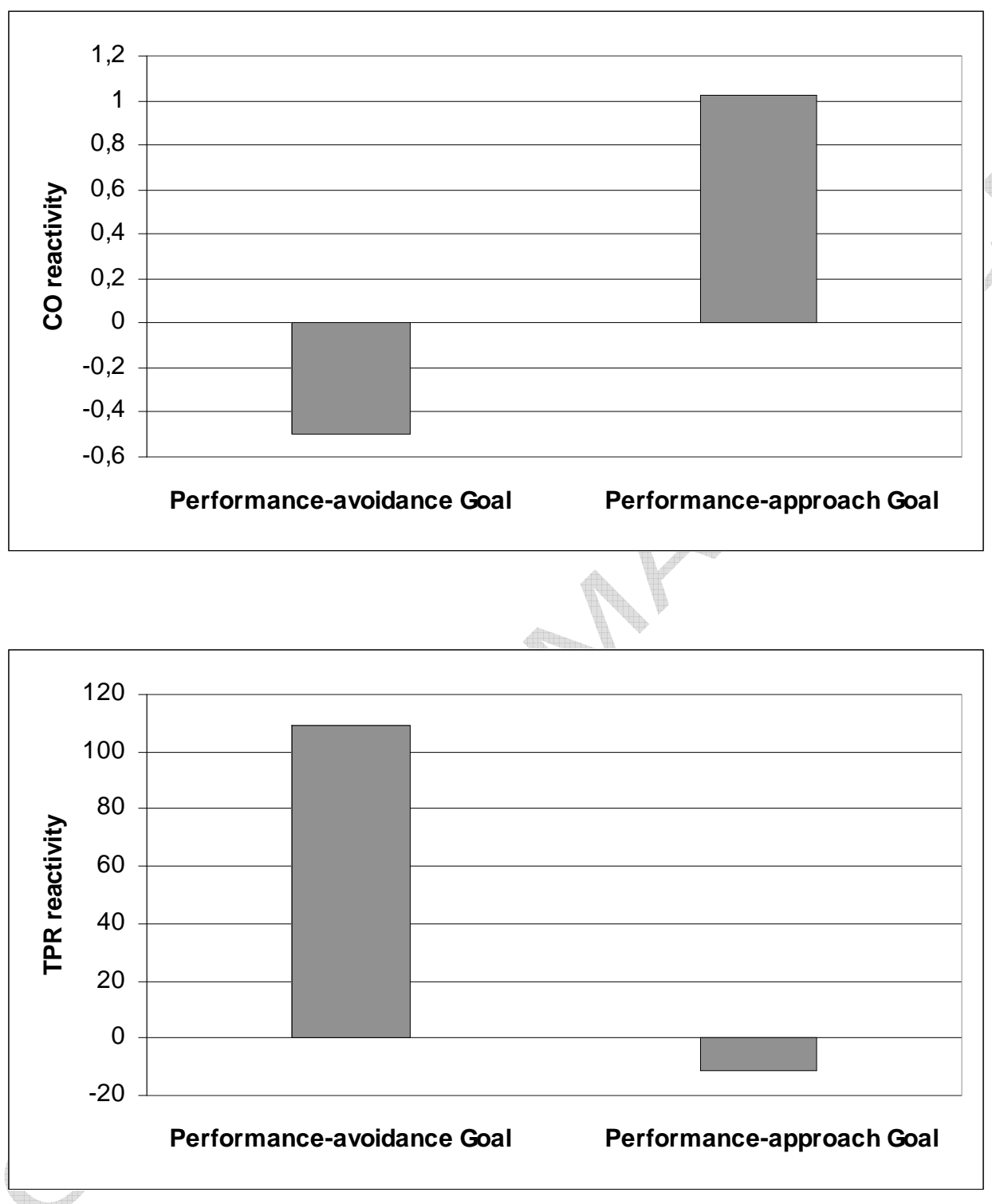
Figure 2.
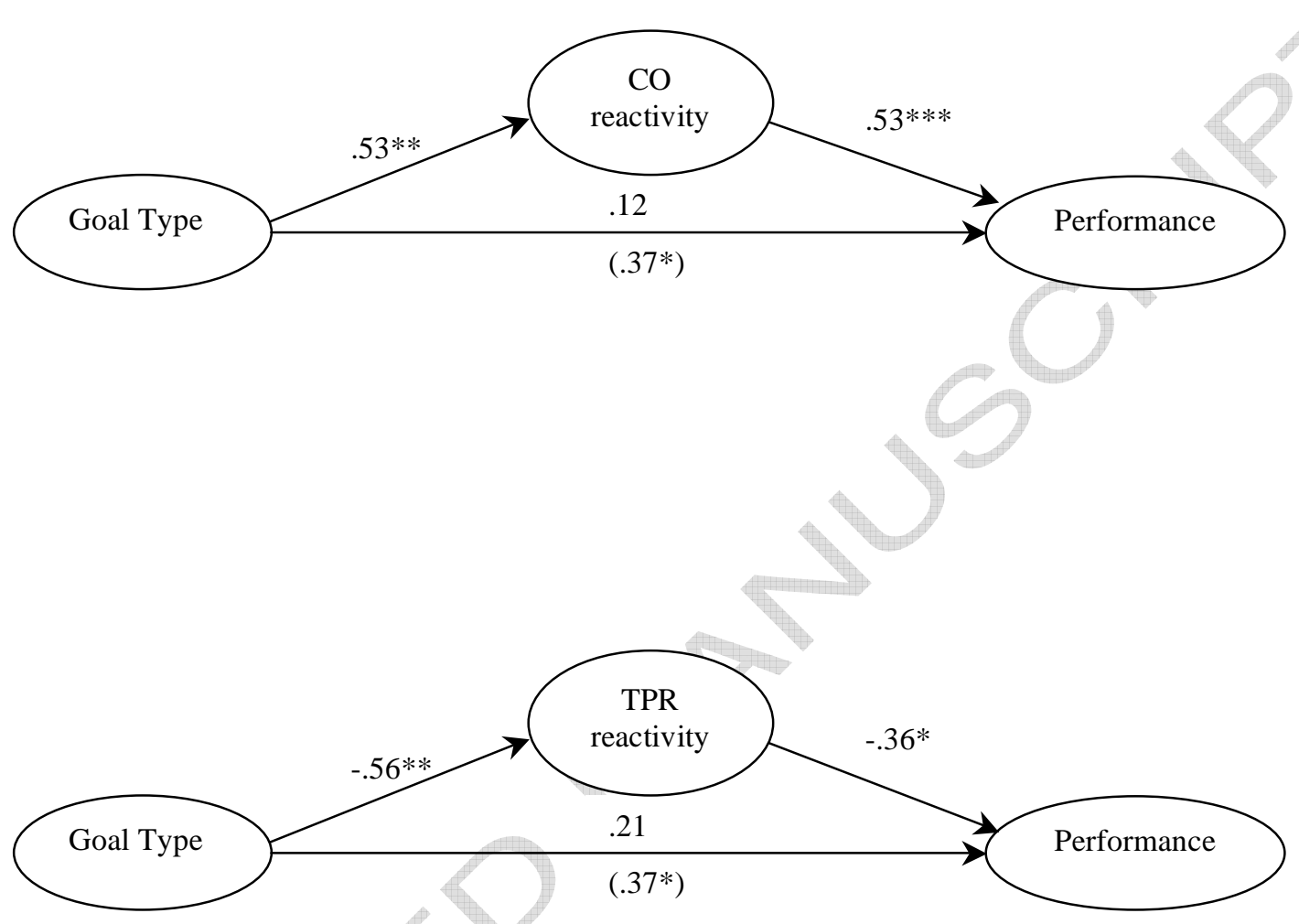

Note. All regression coefficients control for the effects of SAT score and baseline CO (or TPR) on CO (or TPR) reactivity and performance. The coefficient below the arrow from goal type to performance represent the direct relationship between these variables. The coefficients shown above these arrows represent the effect of goal type on performance controlling for $\mathrm{CO}$ (or TPR) reactivity.

$* p<.05 ; * * p<.01 ; * * * p<.001$. 